Social Protection for People with Disabilities in Africa and Asia: A review of programmes for low- and middle-income countries

Matthew Walsham ${ }^{\mathrm{ab} *}$, H. Kuper ${ }^{\mathrm{a}}$, L.M. Banks ${ }^{\mathrm{a}}$ and K. Blanchet ${ }^{\mathrm{a}}$

${ }^{a}$ International Centre for Evidence in Disability, London School of Hygiene \& Tropical Medicine, London, UK; ${ }^{b}$ Global Development Institute, University of Manchester, Manchester, UK (since 2016)

International Centre for Evidence in Disability, London School of Hygiene \& Tropical Medicine, Keppel Street, London WC1E 7HT *email for corresponding author: matthewwalsham@gmail.com 


\section{Social Protection for People with Disabilities in Africa and Asia: A review of programmes for low- and middle-income countries}

Despite greater need for social protection among people with disabilities, there is limited evidence on their inclusion into social protection programmes in low- and middle-income countries. This paper presents the findings from a review of regional and global data sources for Asia-Pacific and Africa to identify social protection programmes that aim to include people with disabilities. It finds a substantial number of programmes in both regions, although there is considerable variation in the quantity and types of programmes within and between regions and countries, as well as between low-and middle-income countries. Further, the quality of data is not sufficient to assess the degree to which these programmes are genuinely inclusive of people with disabilities. As such, it highlights important limitations in the way data is currently being collected that require further attention in the context of the Sustainable Development Goals and the commitment to 'Leave No-one Behind'

Keywords: disability, social protection, low-income countries, middle-income countries, inclusion, Africa, Asia

\section{Introduction}

Social protection encompasses interventions that address financial risks, alleviate poverty and enhance living conditions, including social assistance, social insurance, labour market interventions and social care (Barrientos, 2011; Barrientos \& Hulme, 2009). Social protection is an increasingly important component of strategies for addressing poverty in many low- and middle-income countries (LMIC), especially 
through non-contributory social assistance (cash and in-kind transfers) (Barrientos, 2012, 2013). This is reflected by its inclusion as a specific target under the Poverty Goal of the Sustainable Development Goals (SDGs) to: "implement nationally appropriate social protection systems and measures for all, including floors, and by 2030 achieve substantial coverage of the poor and the vulnerable" (UN General Assembly, 2015). Access to social protection is also included directly or indirectly in an additional four of the other seventeen $\mathrm{SDGs}^{1}$ and can contribute to achieving several others (e.g. protecting against food insecurity, access to quality education) (ILO, 2017).

Disability inclusion within the SDGs is implicit within the above target through the focus on "the poor and the vulnerable". Furthermore, it is highlighted in a number of other specific goals and targets of the SDGs as well as in associated calls to action, particularly the commitment to 'Leave No-one Behind.' (UN General Assembly, 2015; United Nations, 2017). There are estimated to be over one billion people living with a disability, corresponding to $15 \%$ of the world's population (World Health Organisation, 2011) and there is strong evidence that people with disabilities are on average poorer than their peers without disabilities in both developed and developing countries. Across Organisation for Economic Co-operation and Development (OECD) countries, an analysis conducted in 2010 found that the average income of people with disabilities was $15 \%$ lower than people without disabilities, and that $22 \%$ of households with a person with disability were below the poverty threshold, in comparison with $14 \%$ of other households (OECD, 2010). While in a recent systematic review, over $81 \%$ of

\footnotetext{
${ }^{1}$ SDG 3.8 on universal health coverage, SDG 5.4 on recognising the value of unpaid care and domestic work through social protection policies, SDG 8.5 promoting decent work; and SDG 10.4 adopting policies, including in social protection, to achieve greater equality.
} 
studies (122 of 150) identified about LMICs found a positive and statistically significant association between disability and economic poverty (measured through asset ownership, income, expenditures or socioeconomic status) (Banks, Kuper \& Polack, 2017). In total, over half of these studies were conducted in sub-Saharan Africa and Asia-Pacific (22 and 66 studies respectively). The review found that the relationship between disability and economic poverty persisted across age groups, location, disability types and study designs, and provides strong support for the notion of a "disability-poverty" cycle, in which disability is both a potential cause and consequence of multiple dimensions of economic and social exclusion (ibid.).

The relationship between disability and economic poverty may even be underestimated (ibid), as people with disabilities often face additional disability-related expenses (e.g. for medical care, assistive devices, personal assistance, transportation) that can lower their standard of living for a given level of income (Mitra et al., 2017; Palmer et al., 2015; Braithwaite \& Mont, 2009). Additionally, while this review focused only on economic forms of poverty, other research has found disability is linked to more multidimensional forms of poverty as well. For example, people with disabilities globally face lower educational enrolment and attainment (Mizunoya et al., 2016, 2018; Mitra et al., 2013; Filmer, 2008; Kuper et al., 2014) ; higher unemployment and engagement in lower paying, less stable work (Mitra et al., 2013; Mizunoya \& Mitra, 2013; Mitra \& Sambamoorthi, 2008, 2009; Mactaggart et al., 2018); and poorer levels of health and higher healthcare expenditures (WHO, 2011; Mitra et al., 2009, 2013; Mactaggart et al., 2016). Indeed, given the scale of disability globally and the established link with poverty, vulnerability and exclusion, it is likely that the achievement of the SDGs will require specific action to open up pathways out of 
poverty for people with disabilities, not least through the development of inclusive social protection systems (United Nations, 2015).

The inclusion of explicit commitments on disability within the SDGs contrasts with its absence from the earlier Millennium Development Goals (Ghai, 2009; Grech, 2009; United Nations, 2011). Alongside these global developments, countries from the Asia Pacific region agreed their own set of disability-inclusive development goals in 2012 the 'Incheon Strategy' (UN-ESCAP, 2012; 2017) - and efforts have been made to support country level action on disability and development in Africa (UN-DESA, 2016), although policy making at the regional level remains comparatively weak in this area (Lang et al., 2017). However, despite this growing international attention to the issue of disability inclusion within global development, relatively little is currently known about how to achieve the inclusion of people with disabilities in social protection systems, both in terms of mainstream social protection programmes (understood as programmes targeted at the general population or at specific population groups, but not at people with disabilities in particular) and disability-specific social protection schemes (those programmes whose primary focus is people with disabilities). A systematic review on this topic conducted in 2014 , which covered eight electronic databases ${ }^{2}$, found that there is a dearth of high quality, robust evidence, with only 15 peer-reviewed articles identified globally (of which half concerned South Africa) (Banks et al., 2017). Evidence from the limited number of studies that do exist - both those covered in the review and studies published subsequently (Hanass-Hancock \& McKenzie, 2017; Kuper et al., 2016; Bernabe-Ortiz et al., 2016) - suggests that access to social protection

\footnotetext{
2 These were: Web of Science; EconLit; ERIC; ProQuest Health and Medicine Complete; ProQuest Political Science; ProQuest Research Library; ProQuest Social Science Journals; and ProQuest Sociology.
} 
appears to fall far below need. For example, research conducted in Peru and Tanzania showed that greater need for social protection among people with disabilities compared to the general population (in terms of poverty and health needs as well as other socioeconomic measures, such as literacy and dependency ratios) was not translated into higher inclusion rates in social protection programmes that sought to address these issues through cash transfers and community health insurance (Kuper et al., 2016; Bernabe-Ortiz et al., 2016). The research also suggested that commitments to disabilityinclusion through national legal and policy frameworks were not being reflected in the design of individual social protection programmes; that the additional barriers and costs incurred by people with disabilities were not being taken into account in social protection schemes; and that more needs to be done to maximise the potential for social protection systems to facilitate access for people with disabilities to mainstream and specialised services.

In order to understand these evidence gaps at the global level, it is important to analyse existing social protection schemes that seek to include people with disabilities. This article presents the findings from a desk-based review of global databases to analyse social protection programmes in Africa and Asia that aim to include people with disabilities. It provides an indication of the number and types of social protection programmes that exist and identifies regional differences in approach.

\section{Methods}

The desk-review was carried out as part of a broader research project on inclusive social protection systems and was intended to inform the selection of field-research sites. One of the larger study's main objectives was to identify examples of good practice in 
relation to disability-inclusive social protection at a country level. To inform the selection of the country case studies, it was necessary to review existing programmes across the two regions to identify countries that were potentially performing better than their peers.

The desk-review was organised into two consecutive stages carried out in June-July and August-September 2015. Both stages of the review were undertaken by the lead author based on a methodology agreed with the co-authors and an expert steering committee (comprised of academics and policy makers in the fields of disability and social protection), who also reviewed the findings at each stage.

The first stage involved an initial screening process using basic criteria on the functioning of the social protection system to exclude countries with extremely limited systems of social protection (Error! Reference source not found.) as these were considered highly unlikely to be 'best performing' in comparison to other countries in the region. The screening process covered all countries in sub-Saharan Africa ${ }^{3}$ (with the addition of Sudan in Northern Africa), all LMIC countries in Eastern, Southern and South-Eastern Asia, and Melanesia, Micronesia and Polynesia. The World Bank’s Country Policy and Institutional Assessment ratings were used where available to provide a rigorous and comparable measure of the quality of a country's institutional performance, including a specific score for social protection. The ASPIRE database provides an indication of overall social protection coverage. Countries with a low coverage (5\%) were excluded from the study. In addition, very small countries - those

\footnotetext{
${ }^{3}$ All countries in Eastern, Middle, Southern and Western Africa according to the United Nations Statistics Division geographical sub-regions: http://unstats.un.org/unsd/methods/m49/m49regin.htm
} 
with fewer than 1 million inhabitants - were also excluded with the exception of a subset of 'priority countries' from Melanesia, Micronesia and Polynesia agreed with the organisation financing the study (the Australian Department of Foreign Affairs and Trade $)^{4}$.

In the second stage, social protection programme databases were reviewed for all selected countries from nine global databases on social protection identified through web searches and with the input of the expert steering committee (Error! Reference source not found. $)^{5}$. Each database included information on individual social protection programmes, with key features specified (e.g. type, location, dates), although there was no consistent format for this information across the different databases. When information about a programme in a database included a reference to the inclusion of people with disability of any kind, it was included in the review. References to the inclusion of people with specific impairments (e.g. 'blind people' or 'the mentally ill') were also regarded as a justification to include the programme.

Data on programmes extracted from the databases were recorded based on a predetermined extraction table and themes (

\footnotetext{
${ }^{4}$ These were: Tonga, Solomon Islands, Fiji, Samoa, Vanuatu, New Caledonia, Papua New Guinea and the Cook Islands.

${ }^{5}$ These were: Social Security Inquiry; Social Security Programs Throughout the World; Social Protection Index (consultant country reports); Responses to call for submissions by Special Rapporteur on the Rights of Persons with Disabilities; State Party Reports to Committee on the Rights of Persons with Disabilities; Social Assistance in Developing Countries Database Version 5.0; Mapping report on social protection programmes for people disabilities; Disability and social assistance database; and the Disability Benefits Scheme Database
} 
). The themes concerning general programme information were developed by combining the headings used by the International Labour Organization (ILO) Social Security Inquiry (ILO, 2005) with the World Bank’s “ASPIRE” Atlas of Social Protection categories and sub-categories for social protection programme classification (World Bank, n.d.). In addition, seven sub-themes were included related to different aspects of disability-inclusion within programmes. These were based on an 'inclusive social protection checklist' developed as part of a previous research project carried out by the authors ${ }^{6}$, which offered guidance to policy makers on how to incorporate disability-inclusion into existing or planned social protection programmes, including the importance of developing meaningful participation mechanisms and of collecting disaggregated data on beneficiaries with disabilities and budget allocations for any additional services or benefits targeted.

For the majority of fields, this approach enabled standardised data to be collected from the different databases, even though there was no single approach to classification of data across the different sources. This was because there were either a limited number of responses available (e.g. 'public or private', 'statutory or non-statutory' or the ASPIRE categories and sub-categories for social protection schemes) or a numerical figure was required. The exceptions were the fields for 'scheme benefits', 'definition of disability', 'inclusion criteria', 'additional services/benefits' and 'participation mechanisms' where a summary was provided using the original language of the source material wherever possible. This enabled detailed information on the specifics of each scheme and the efforts being made to include people with disabilities to be captured.

\footnotetext{
${ }^{6}$ www.disabilitycentre.1shtm.ac.uk/inclusive-social-protection-project
} 
This approach also allowed for data to be extracted in a consistent and reliable manner from those sources that presented data in text-based report format rather than structured as a database. In particular, the Responses to call for submissions by Special Rapporteur on the Rights of Persons with Disabilities and the State Party Reports to the Committee on the Rights of Persons with Disability (United Nations, 2015b), in which individual country reports used the same overall format - including in the latter case a specific section on social protection - but varied widely in the selection and presentation of information within the report itself. Similarly, data from the Asian Development Bank's Social Protection Index consultant country reports - which were commissioned to provide the data for the Index itself - presented some information in table format but often included further detail in the accompanying narrative text.

All data sources were accessed in August 2015 and findings were recorded in an Excel database. Where data was available for a programme for multiple years or in multiple databases, only the most recent entry was included. Similarly, where programmes had changed names or merged with one another, only the latest version of the programme was recorded. Analysis was carried out using Excel once data had been collected for both Africa and Asia-Pacific. As well as comparing countries by region and sub-region, differences between low- and middle-income countries were analysed, as were differences between Francophone and non-Francophone countries in Africa.

\section{Results}

Through the screening process, six countries in Asia were excluded (Bhutan, Maldives, Brunei Darussalam, Cambodia, Laos and Myanmar), as were all countries in Melanesia, Micronesia and Polynesia not identified as "priority countries" by DFAT. Cambodia 
and Laos were excluded as their total spending on social protection in ADB's Social Protection Index was under 1\% of GDP. Spending figures were not available for Myanmar, but their CPIA Social Protection Rating was 2 out of 6, the joint lowest in Asia-Pacific alongside Micronesia and the Marshall Islands. The remaining countries including all those in Melanesia, Micronesia and Polynesia - each had populations under 1 million.

Nineteen countries in Africa were excluded (Comoros, Djibouti, Eritrea, Madagascar, Malawi, Seychelles, Somalia, South Sudan, Zambia, Zimbabwe, Chad, Equatorial Guinea, Sao Tome and Principe, Botswana, Core D’Ivoire, Guinea-Bissau, Niger, Nigeria and Senegal). Six of these countries had populations of under 1 million people (Comoros, Djibouti, Seychelles, Equatorial Guinea, Sao Tome and Principe and Cape Verde). Notably, a larger number of countries in Africa scored very poorly in the CPIA Social Protection Rating (Eritrea, Madagascar, Zimbabwe, Central African Republic and Guinea-Bissau all scored 2 out of 6 and South Sudan had a score of 1.5), while Zambia, Niger and Nigeria all had very low social protection coverage according to the ASPIRE database (under 5\% of the population). Finally, Botswana and Senegal were excluded because - along with Djibouti - they were the only three countries across the two regions to have no formal social security programmes in place for people with disabilities according to the International Social Security Association.

The full search therefore covered 22 countries in Asia Pacific and 30 countries in subSaharan Africa. In total, 215 social protection programmes with some reference to disability within their design were identified in Asia Pacific, an average of 9.8 programmes per country. 151 programmes were identified in Africa, an average of 5 
programmes per country (see Table 4). No entries were found for two countries (New Caledonia and Tonga), both in Melanesia, Micronesia and Polynesia (MM\&P).

Within Asia Pacific there was substantial variation between regions, with southern Asia having the most schemes (at 16.7 programmes on average), compared to an average of only 3.3 schemes for MM\&P. Afghanistan was the only notable exception to this trend in southern Asia, with a total of just four schemes. Eastern Asia and South-Eastern Asia both had a similar number of programmes (an average of 12.5 and 10.7 respectively). Within these regions Thailand and Timor-Leste had the fewest schemes (8), while Vietnam had the most (17). The variation between African regions was less extreme, with Eastern Africa having the most (8.3 on average) and Western Africa the least (3.5 on average $)^{7}$. However, variation between individual countries could still be substantial with, for example, Kenya having 16 programmes, while Angola had only one.

Across both Asia Pacific and Africa, there was a relationship between the income category of countries and the average number of schemes in place, with an average of eight schemes per country in middle-income countries, compared to an average of 5 in low-income countries. However, differences were smaller than those between regions and sub-regions.

The overwhelming majority of identified programmes in all regions were public programmes rather than private sector initiatives: 201 (93\%) in Asia Pacific and 146 $(97 \%)$ in Africa. A very wide variety of ministries, government bodies and agencies

\footnotetext{
${ }^{7}$ Excluding Northern Africa where only Sudan was included in the review and had just two schemes.
} 
were responsible for these programmes, including ministries of labour, social welfare, health, finance, rural development, education as well as provincial and local government and social security, social insurance and provident funds.

It was more difficult to establish whether programmes were statutory or not because the legal basis of schemes was not always clearly indicated in the databases. In Asia Pacific, 98 schemes (46\%) were established on a statutory basis, $11(5 \%)$ were nonstatutory and for 111 schemes (49\%), not enough information was provided in the database to classify the scheme. In Africa, 113 programmes (75\%) were statutory in basis, 8 non-statutory (5\%) and the status of $30(20 \%)$ could not be established. One of the reasons why the legal basis of schemes in Africa was generally easier to establish was that a much larger proportion of identified schemes were contributory programmes for formal sector workers (where employees must have made contributions to a scheme in order to participate, usually alongside employer and governmental contributions), rather than non-contributory schemes (where beneficiaries are enrolled according to a set of criteria - e.g. poverty, age, disability - and no financial contribution is required to join), particularly in middle and western Africa (see Figure 1). As Error! Reference source not found.2 illustrates, this primarily reflects differences between Francophone and non-Francophone Africa. No non-contributory schemes at all were found in 11 countries in Francophone Africa with the only notable exceptions were Mauritius (10 non-contributory programmes) and Gabon (4 noncontributory programmes).

The division between contributory and non-contributory schemes is also reflected in the proportion of social assistance (non-contributory transfers targeted at the poor), social insurance (contributory and non-contributory measures to protect households against 
risk) and labour market schemes (designed to promote employment and protect workers) in different sub-regions (see Figure 3) (Devereux \& Sabates-Wheeler, 2004; Banks et al., 2017). Social assistance is dominant in Eastern, Southern and SouthEastern Asia as well as to a lesser degree in MM\&P, Eastern and Southern Africa. In Middle and Western Africa, social insurance schemes accounted for the largest proportion of schemes. Labour market programmes made up a small percentage of programmes in all regions, accounting for only $14 \%$ of schemes overall.

Under these three broad categories, there was substantial diversity in terms of the specific kinds of schemes in both Asia Pacific and Africa (see Error! Reference source not found.) using the World Bank's ASPIRE sub-categories for social protection programme classification (World Bank, n.d.). Contributory and non-contributory pensions were important in both regions along with various kinds of cash and in-kind transfers, fee-waivers and subsidies. Unconditional cash transfers were the most common form of social assistance in Africa, but were less common in Asia-Pacific. The significance of 'other' kinds of social assistance and social insurance schemes - i.e. those that do not fit the standard ASPIRE categories - is also particularly noticeable in both regions, although with important differences. In Asia Pacific, the main subcategories of 'other' social assistance were: scholarships and education benefits (12), social care services and housing (7), health benefits (4) and mixed schemes (8). For social insurance, the main sub-categories were: occupational injuries benefits (12), health insurance (7) and mixed schemes (16). The latter category are - with the exception of a single non-contributory scheme in Mongolia - statutory, contributory social insurance schemes consisting of a pension or retirement benefit with some combination of maternity, disability and sickness or death benefits. In Africa, 'other' 
social assistance was a much smaller category with only four entries, but 'other' social insurance primarily consisted of occupational injuries benefits (26) and maternity / paternity benefits (10). In both regions, it should be noted that although the database captures a variety of national or large-scale contributory and non-contributory health insurance or work injury schemes, as well as mixed contributory social insurance schemes covering a variety of benefits including healthcare, other health financing mechanisms were not generally listed in the source databases, including tax-financed public health care as well as many non-statutory forms of health insurance targeted at the informal sector or specific groups, such as micro-health insurance.

The majority of schemes in both Asia Pacific and Africa that included some disability dimension were mainstream programmes rather than disability-specific schemes $(67 \%$ and $79 \%$ respectively). In Francophone Africa, the figure was even higher at $88 \%$, with $95 \%$ of schemes in Western Africa mainstream rather than disability specific. The only sub-region with more disability-specific schemes than mainstream schemes was East Asia, where there were 14 disability-specific programmes identified in China and Mongolia out of 25 in total.

In terms of benefits, in Asia two thirds of programmes offer cash or a combination of cash and in-kind benefits ${ }^{8}$, with one third offering in-kind benefits alone (e.g. food, health care, training) (Error! Reference source not found.). It is noticeable that over half of benefits were either ad-hoc or lump-sum benefits rather than regular, periodic benefits. This reflects the wide range of "other" social assistance and social insurance

\footnotetext{
${ }^{8}$ For the purposes of categorisation, in-kind was taken to mean non-cash items as well as services.
} 
schemes noted above, including provident funds, educational scholarships, fee waivers and other funds that provide one-off support to people with disabilities along with labour market programmes (vocational training and other employment services). In Africa, a smaller percentage of schemes were ad-hoc or lump sum, with periodic or mixed-benefit schemes accounting for $74 \%$ of programmes. In-kind programmes also represented a smaller share in Africa: only $15 \%$ of schemes, compared to $60 \%$ for cash and $25 \%$ for combined cash and in-kind.

In terms of number of beneficiaries, $39 \%$ of schemes in Asia Pacific had over 100,000 beneficiaries, with similar proportions having between $10,000<100,000(18 \%)$ and under 10,000 (17\%). There were no data for 27\% of schemes (see Error! Reference source not found.4). In Africa, there were no data for over half of schemes (53\%) while $20 \%$ of schemes had over $100,000,17 \%$ had $10,000<100,000$ and $10 \%$ had under 10,000 beneficiaries. Notably, out of 144 mainstream schemes in Asia, a figure for the number of beneficiaries with disabilities was only available in 37 programmes; while in Africa there was only data on the number of beneficiaries with disabilities for 30 out of 118 mainstream schemes in total.

For other categories, it was more difficult to extract meaningful data. In terms of expenditure, there was data for 150 of the 215 schemes in Asia Pacific, but the absence of a standardised approach to reporting spending across the different data sources prevents meaningful comparison across schemes and countries. This is because although attempts were made to collect the most up-to-date figure for total annual expenditure on the programme, the latest year available varied widely (from 2003 to 2013) or, in some cases, either aggregate data was given for multiple years or the year was not specified. Figures were also generally provided in local currencies rather than 
US dollars, which further complicates comparisons between programmes given that the data was from a wide range of years. It was also sometimes partial in nature, for example government contributions towards a contributory social insurance scheme, or expenditure on claims and benefits, rather than total expenditure on the scheme. These issues also applied to data on the specific budget allocation related to disability, although this was even more limited and was only available for 28 out of the 144 mainstream schemes in Asia.

In Africa, expenditure data was only available for 60 out of 151 schemes and, for the reasons noted above in relation to Asia-Pacific, the lack of standardisation also makes meaningful comparison difficult. Of note, 36 out of the 60 schemes for which data were available were contributory social insurance schemes, which reflects the greater proportion of contributory schemes for formal sector workers in Africa and the likelihood that they have a more formalised, legal basis along with annual fiscal reporting requirements. Once again, data on expenditure on disability in mainstream schemes was only available in a small number of instances (30 out of 118 mainstream schemes).

It was possible to extract basic data on the inclusion criteria for most schemes in Asia (182 out 215) but these were extremely varied in nature, ranging from very specific formal criteria for contributory social security schemes (often based on the "percentage" of disability) to vague assertions that people with disabilities would be "given priority". More specific information on the approach taken to assessing disability was only available in 41 schemes, with the majority of these (28) being medical in approach, where decisions on the 'level' of disability of an individual are taken by a doctor or 
medical board appointed by the scheme. The exceptions were countries in which a disability certificate has been introduced and was being used to determine eligibility for some schemes (China, Pakistan, Bangladesh, Nepal and Vietnam) and a cash transfer for people with disabilities Indonesia where programme staff were tasked with determining eligibility.

In Africa, the inclusion criteria of schemes were similarly complex, although information available for most schemes (130 out of 156), and once again reflected the greater emphasis on formal social security schemes. However, information was available on the assessment process in only 36 schemes, of which 28 were medical in approach. Exceptions in Africa include a cash transfer specifically for people with severe disabilities in Kenya in which eligibility was based on an assessment of functional impairment in the domains of feeding, toiletry and sanitary needs; two schemes in Tanzania and Uganda where the Washington Group Short Set of Questions was used to identify individuals with disabilities as while determining 'vulnerability' at the household level; and a social assistance scheme in Mozambique in which 'permanentes' (community agents) were involved in determining eligibility alongside medical assessment.

In terms of participation mechanisms, there were two schemes in Asia Pacific where it was possible to identify that consultations had taken place with the disability movement. These were both in the Philippines and were identified through the submission to the Special Rapporteur on the Rights of Persons with Disabilities in 2015. In Africa, there were six schemes in which participation mechanisms could be identified, either through the submission to the Special Rapporteur or through country submissions to the Committee on the Rights of Persons with Disabilities. These were national advisory 
councils ( 3 schemes), grievance mechanisms (1 scheme) and involvement of disability groups in targeting or fund disbursement ( 2 schemes). As this indicates, it is not possible to make a robust analysis of inclusive mechanisms through the existing data sources.

\section{Discussion}

The data presented in this study were sufficient to identify broad trends between different regions in terms of approaches to inclusion of people with disabilities in social protection. With the exception of MM\&P, Asia has a greater number of schemes in place than Africa, and these are more likely to be non-contributory social assistance schemes than contributory social insurance. Within Africa, there is substantial difference between Francophone and non-Francophone countries, with contributory social insurance dominant in Western and Central Africa, while social assistance predominates in the Eastern and Southern Africa. Across both Africa and Asia-Pacific, middle-income countries had more schemes on average than low-income countries, although regional variations had a larger effect. Labour market programmes made up only a small proportion of programmes in all regions.

Almost all schemes identified were public rather than private in nature. Most schemes in Africa were established on a statutory basis, once again reflecting the larger proportion of formal social security programmes, while in Asia it was only possible to establish this for just under half of cases, with most of the remaining schemes uncategorised due to lack of information. Contributory and non-contributory pensions, cash and in-kind transfers and fee-waivers and subsidies were common in all regions. However, the ASPIRE sub-categories appear to be inadequate to fully capture the variety of schemes that aim to include people with disabilities. In particular, common 
types of schemes that had to be recorded as "other" social assistance or social insurance were scholarships and education benefits, social care and housing support, occupational injuries benefits, maternity/paternity benefits (especially in Africa) and health insurance.

Mainstream programmes that include people with disabilities predominated over disability specific programmes. The exception to this pattern was East Asia, where both China and Mongolia had a wide range of disability-targeted social assistance, social insurance and labour market programmes alongside mainstream programmes that aimed to include people with disabilities. Programmes in Asia tended to be larger than in Africa, although the African data was poor on this issue with no data in over half of the schemes (in Asia, the figure was just over a quarter). Inclusion criteria varied widely in both Africa and Asia from highly specific formula (usually related to contributory social security programmes) to vague statements "prioritising" people with disabilities. In the relatively small number of cases where information was available on the assessment process itself, these were mostly medical in nature.

Data on the number of people with disabilities reached through programmes and the budget allocated to disability specifically was generally not available or provided in a way that makes cross country comparison very challenging. Even within individual countries that had large numbers of programmes with some disability component, it was challenging to assess the degree to which that corresponds to coverage of people with disabilities. For example, in India, there was no data on the number of people with disabilities included in the 16 mainstream schemes identified; and a crude total of beneficiaries from the 9 disability-targeted schemes comes to just over 6 million people, 
or less than $0.5 \%$ of the total population of India. Figures on disability prevalence in India vary widely, with WHO World Health Survey suggesting a figure as high as $25 \%$ (WHO, 2011), but the combined coverage of the nine schemes above is well below even the more modest $2.2 \%$ of the population identified by the 2011 census (Saika et al, 2016). In Thailand, although the formal social security scheme was recorded as having 9.42 million members in 2012 , only 1,286 claimants for the disability pension were reported, while the figure for those accessing rehabilitation services through the workmen's compensation fund was 5,023 over a fifteen year period to 2010. No data were available for the other three mainstream schemes, and only one of the three disability schemes had substantial coverage (of 1,235,378 people in 2010), although this alone represented $1.8 \%$ of the population in 2010 , easily surpassing the coverage for all India's programmes combined. This highlights both the severe limitations in the data in both countries and the fact that the total number of schemes in a country is unlikely to be a good indicator of actual population coverage in most cases.

Information on participation mechanisms was essentially absent from the data sources, with only two cases in Asia and six cases in Africa almost all identified through country submissions to the Special Rapporteur on the Rights of Persons with Disabilities or the Committee on the Rights of Persons with Disabilities.

Many of the trends in the data reflect broader characteristics of the social protection landscape, for example the emphasis on contributory programmes in Francophone Africa which continue to focus primarily on schemes for formal works rather than prioritising social assistance for the informal sector (Holmes \& Lwanga-Ntale, 2012; Devereux \& White, 2010) or the large number of programmes in South Asia (Barrientos 
\& Hulme, 2008). It is interesting to note the wide diversity of programmes in AsiaPacific especially, indicating the need for a systematic approach if this highly complex and fragmented landscape of programmes is to be reformed, but also the challenges this will entail.

A key finding from the study supports the frequently stated concern that evidence and data on the inclusion of people with disabilities in social protection at present is inadequate (Banks et al., 2017; Gooding \& Marriot, 2009; Mitra, 2005). The review of global databases demonstrates that none are currently fit-for-purpose in terms of generating comparable data on the degree to which the social protection system in a particular country is inclusive of people with disabilities. The World Bank's ASPIRE database - compiled from nationally representative household surveys - contains no information on disability at all. The most comprehensive sources of information on individual social protection programmes worldwide are the ILO's Social Security Inquiry and the International Social Security Association's Social Security Programs Throughout the World. However, the quality of the former is highly variable across countries; while the latter places a significant focus on formal, contributory social security programmes over social assistance or other kinds of social protection. Other data sources such as the country reports for the Asian Development Bank's Social Protection Index and the Social Assistance in Developing Countries Database offer more detail on individual programmes but provide a "snapshot" rather than regularly updated source of information. In none of these data sources is information on disability systematically included. 
The only sources that provided some detail on specific aspects of programme design such as participation mechanisms were country submissions to the Special Rapporteur on the Rights of Persons with Disabilities and country reports to the Committee for the Rights of People with Disabilities. The information countries chose to provide in these submissions varies widely. Nonetheless, the latter could become a useful source of information over time as countries are required to submit a report every four years and this has to contain a chapter on access to social protection. The Disability Benefits Database also contains some useful information on a selection of social assistance schemes but it is relatively narrow in scope (non-contributory, social assistance programmes only), mostly drawn from other databases, and is not being regularly updated.

The poor quality of data is of particular importance in the context of the SDGs, where disaggregated data on disability will be essential to monitoring progress towards the commitment to "Leave No-one Behind". Without a systematic approach to improve country level data on this issue and to gather it together at regional and global levels, it will be impossible to track the degree to which the promised extension of social protection programme coverage is inclusive of people with disabilities. Adding disability-inclusion as an explicit indicator with the Social Protection Index in Asia would be a welcome start, but will not address the need for ongoing data collection on this issue. Ideally, any initiative in this area would include clearer indications of the resource allocation for disability and number of people with disabilities included in mainstream social protection programmes. There will be challenges in terms of identifying resource allocations that are specific to disability, but the increasing use of tools such as the Washington Group Short Set of Questions (Madans, Loeb \& Altman, 
2011) in national household surveys should at least allow for the ASPIRE database to begin to collect data on the number of people with disabilities in programmes.

An important limitation of the data is that it is static in nature which does not make it possible to identify changes over time. It also means that the data may contain some programmes that are no longer in operation. The quality of the data set reflects the limitations of the data sources themselves, for example the highly variable quality of data and information across different countries. A particular challenge relates to financial data on resources committed for programmes which was of poor quality, particularly specific data on resources allocated to people with disabilities in mainstream programmes. A key strength of the approach adopted was the use of multiple databases to collate the most comprehensive available data on disability inclusion within social protection programmes across Africa and Asia. The systematic approach used maximised the comparability of the extracted data and can help inform the development of improved approaches to standardised data collection on social protection for people with disabilities at the country, regional and global level. This makes the identification of major gaps in the available data an important finding in itself.

\section{Conclusion}

The findings of the study provide the first overview of social protection programmes for people with disabilities in Africa and Asia. They indicate that while attention to this topic has been lacking (Palmer, 2013; ) this does not mean that there are no programmes already in place. However, although the data enables broad trends in regional and country approaches to be identified, it is not sufficient to assess either the quality of these programmes or the degree to which people with disabilities are actually being 
included within the social protection system as a whole. In the context of the SDGs, further work is needed to establish more rigorous, comparable data on the inclusion of people with disabilities in social protection programmes at a country, regional and global level. 


\section{Acknowledgements}

The authors would like to thank the funder of the study, the Australian Department of

Foreign Affairs \& Trade, as well as the expert steering committee for the project whose advice during the review was invaluable. 


\section{References}

Banks, L. M., Mearkle, R., Mactaggart, I., Walsham, M., Kuper, H., \& Blanchet, K. (2017). Disability and social protection programmes in low-and middle-income countries: a systematic review. Oxford Development Studies, 45(3), 223-239.

Banks, L. M., Kuper, H. \& Polack, S. (2017). Poverty and Disability in low-and middleincome countries: A systematic review. PloS one, 12(12): p. e0189996.

Bernabe-Ortiz, A., Diez-Canseco, F., Vasquez, A., Kuper, H., Walsham, M., \& Blanchet, K. (2016). Inclusion of persons with disabilities in systems of social protection: a population-based survey and case-control study in Peru. $B M J$ open, 6(8), e011300.

Barrientos, A. (2011). Social protection and poverty. International Journal of Social Welfare, 20(3), 240-249. doi: 10.1111/j.1468-2397.2011.00783.x

Barrientos, A. (2012). Social Transfers and Growth: What Do We Know? What Do We Need to Find Out? World Development, 40(1), 11-20. doi: http://dx.doi.org/10.1016/j.worlddev.2011.05.012

Barrientos, A. (2013). Social Assistance in Developing Countries. Cambridge: Cambridge University Press.

Barrientos, A., \& Hulme, D. (2008). Embedding social protection in the developing world. In A. Barrientos \& D. Hulme (Eds.), Social protection for the poor and the poorest: Concepts, policies and politic, 315-330. Basingstoke, UK: Palgrave Macmillan.

Barrientos, A., \& Hulme, D. (2009). Social Protection for the Poor and Poorest in Developing Countries: Reflections on a Quiet Revolution: Commentary. Oxford Development Studies, 37(4), 439-456.

Braithwaite, J., \& Mont, D. (2009). Disability and poverty: a survey of World Bank poverty assessments and implications. ALTER-European Journal of Disability Research/Revue Européenne de Recherche sur le Handicap, 3(3), 219-232. 
Devereux, S., \& Sabates-Wheeler, R. (2004). Transformative social protection. IDS Working Paper 232, Brighton: IDS.

Devereux, S., \& White, P. (2010). Social Protection in Africa: Evidence, Politics and Rights. Poverty \& Public Policy, 2(3), 53-77. doi: 10.2202/1944-2858.1078

Filmer, D. (2008). Disability, poverty, and schooling in developing countries: results from 14 household surveys. The World Bank Economic Review, 22(1), 141-163.

Ghai, A. (2009). Disability and the millennium development goals: A missing link. Journal of Health Management, 11(2), 279-295.

Gooding, K., \& Marriot, A. (2009). Including persons with disabilities in social cash transfer programmes in developing countries. Journal of International Development, 21(5), 685-698. doi: 10.1002/jid.1597

Grech, S. (2009). Disability, poverty and development: Critical reflections on the majority world debate. Disability \& Society, 24(6), 771-784.

Hanass-Hancock, J., \& McKenzie, T. C. (2017). People with disabilities and incomerelated social protection measures in South Africa: Where is the gap?. African Journal of Disability, 6(1), 1-11.

Holmes, R., \& Lwanga $\square$ Ntale, C. (2012). Social protection in Africa: A review of social protection issues in research. Nairobi: Partnership for African Social and Governance Research.

International Labour Organization. (2005). ILO Social Security Inquiry Manual: First Inquiry, 2005. Geneva: International Labour Organization.

International Labour Organization. (2017). World Social Protection Report 2017-19: Universal social protection to achieve the Sustainable Development Goals. Geneva: International Labour Organization. 
Kuper, H., Monteath-van Dok, A., Wing, K., Danquah, L., Evans, J., Zuurmond, M., \& Gallinetti, J. (2014). The impact of disability on the lives of children; crosssectional data including 8,900 children with disabilities and 898,834 children without disabilities across 30 countries. PloS one, 9(9), e107300.

Kuper, H., Walsham, M., Myamba, F., Mesaki, S., Mactaggart, I., Banks, M., \& Blanchet, K. (2016). Social protection for people with disabilities in Tanzania: a mixed methods study. Oxford Development Studies, 44(4), 441-457.

Lang, R., Schneider, M., Kett, M., Cole, E., \& Groce, N. (2017). Policy Development: An Analysis of Disability Inclusion in a Selection of African Union Policies Inclusive. Development Policy Review. doi: 10.1111/dpr.12323

Mactaggart, I., Kuper, H., Murthy, G. V. S., Sagar, J., Oye, J., \& Polack, S. (2016). Assessing health and rehabilitation needs of people with disabilities in Cameroon and India. Disability and rehabilitation, 38(18), 1757-1764.

Mactaggart, I., Banks, L. M., Kuper, H., Murthy, G. V. S., Sagar, J., Oye, J., \& Polack, S. (2018). Livelihood opportunities amongst adults with and without disabilities in Cameroon and India: A case control study. PloS one, 13(4), e0194105.

Madans, J. H., Loeb, M. E., \& Altman, B. M. (2011). Measuring disability and monitoring the UN Convention on the Rights of Persons with Disabilities: the work of the Washington Group on Disability Statistics. BMC public health, $11(4), \mathrm{S} 4$.

Mitra, S. (2005). Disability and Social Safety Nets in Developing Countries. Washington, DC: World Bank.

Mitra, S., \& Sambamoorthi, U. (2008). Disability and the rural labor market in India: evidence for males in Tamil Nadu. World Development, 36(5), 934-952. 
Mitra, S., \& Sambamoorthi, U. (2009). Wage differential by disability status in an agrarian labour market in India. Applied Economics Letters, 16(14), 1393-1398.

Mitra, S., Findley, P. A., \& Sambamoorthi, U. (2009). Health care expenditures of living with a disability: total expenditures, out-of-pocket expenses, and burden, 1996 to 2004. Archives of physical medicine and rehabilitation, 90(9), 15321540.

Mitra, S., Posarac, A., \& Vick, B. (2013). Disability and poverty in developing countries: a multidimensional study. World Development, 41, 1-18.

Mitra, S., Palmer, M., Kim, H., Mont, D., \& Groce, N. (2017). Extra costs of living with a disability: A review and agenda for research. Disability and Health, 10(4), 475-484.11.

Mizunoya, S., \& Mitra, S. (2013). Is there a disability gap in employment rates in developing countries?. World Development, 42, 28-43.

Mizunoya, S., Mitra, S., \& Yamasaki, I. (2016). Towards Inclusive Education: The impact of disability on school attendance in developing countries. Innocenti Working Paper No. 2016-03. Retrieved from: http://dx.doi.org/10.2139/ssrn.2782430

Mizunoya, S., Mitra, S., \& Yamasaki, I. (2018). Disability and school attendance in 15 low-and middle-income countries. World Development, 104, 388-403.

OECD. (2010). Sickness, Disability and Work: Breaking the Barriers: A Synthesis of Findings Across OECD Countries. Paris:Organisation for Economic Cooperation and Development.

Palmer, M. (2013). Social Protection and Disability: A Call for Action. Oxford Development Studies, 41(2), 139-154. doi: 10.1080/13600818.2012.746295

Palmer, M., Groce, N., Mont, D., Nguyen, O. H., \& Mitra, S. (2015). The Economic Lives of People with Disabilities in Vietnam. PLoS One, 10(7), e0133623. 
Saikia, N., Bora, J. K., Jasilionis, D., \& Shkolnikov, V. M. (2016). Disability Divides in India: evidence from the 2011 census. PloS one, 11(8), e0159809.

UN Department of Economic and Social Affairs. (2016). Toolkit on Disability for Africa. New York: United Nations.

UN Economic and Social Commission for Asia and the Pacific. (2012). Incheon Strategy to "Make the Right Real" for Persons with Disabilities in Asia and the Pacific. Bangkok: United Nations.

UN Economic and Social Commission for Asia and the Pacific. (2017). Building Disability $\square$ Inclusive Societies in Asia and the Pacific: Assessing Progress of the Incheon Strategy. Bangkok: United Nations.

UN General Assembly. (2015). Transforming our world: the 2030 Agenda for Sustainable Development. New York: United Nations.

United Nations. (2011). Disability and the Millennium Development Goals: A Review of the MDG Process and Strategies for Inclusion of Disability Issues in Millennium Development Goal Efforts. New York: United Nations.

United Nations. (2015a). Report of the Special Rapporteur on the rights of persons with disabilities: the right of persons with disabilities to social protection. New York: Office of the High Commissioner for Human Rights.

United Nations (2015b). Responses to call for submissions by Special Rapporteur on the Rights of Persons with Disabilities and the State Party Reports to the Committee on the Rights of Persons with Disability. Retrieved from: http://www.ohchr.org/EN/Issues/Disability/SRDisabilities/Pages/SocialProtectio n.aspx

United Nations. (2017). The Sustainable Development Goals Report. New York: United Nations Department of Economic and Social Affairs. 
World Bank. (n.d.). ASPIRE PROGRAM CLASSIFICATION. from

http://siteresources.worldbank.org/EXTSOCIALPROTECTION/Resources/2826 36-1408630568347/ASPIRE_program_classification.pdf

World Health Organisation. (2011). World Report on Disability. Geneva: World Health Organisation. 
Table 1: Inclusion criteria for full desk-review of countries

\begin{tabular}{|l|l|l|l|}
\hline Criteria & Threshold & Applicability & Source \\
\hline Population & $>1$ million & $\begin{array}{l}\text { All countries except Melanesia, } \\
\text { Micronesia and Polynesia }\end{array}$ & UN \\
\hline $\begin{array}{l}\text { Country Policy \& } \\
\text { Institutional Assessment } \\
\text { (CPIA) social protection } \\
\text { rating }\end{array}$ & $\geq 2$ (out of 6) & $\begin{array}{l}\text { International Development } \\
\text { Association (IDA) eligible } \\
\text { countries only }\end{array}$ & $\begin{array}{l}\text { CPIA database, } \\
\text { World Bank }\end{array}$ \\
\hline $\begin{array}{l}\text { Social Protection } \\
\text { Coverage }\end{array}$ & $\begin{array}{l}>5 \% \text { of } \\
\text { population }\end{array}$ & $\begin{array}{l}\text { Only where data is available } \\
\text { from 2010 onwards }\end{array}$ & $\begin{array}{l}\text { ASPIRE database, } \\
\text { World Bank }\end{array}$ \\
\hline $\begin{array}{l}\text { Formal Social Security } \\
\text { Disability Benefits }\end{array}$ & Yes/No & $\begin{array}{l}\text { All countries with ISSA country } \\
\text { data }\end{array}$ & $\begin{array}{l}\text { International Social } \\
\text { Security Association }\end{array}$ \\
\hline
\end{tabular}


Table 2: Characteristics of the databases reviewed in 2015

\begin{tabular}{|c|c|c|c|}
\hline Database name & $\begin{array}{l}\text { Geographical } \\
\text { Coverage }\end{array}$ & $\begin{array}{l}\text { Year of } \\
\text { data } \\
\text { collection }\end{array}$ & Database owner \\
\hline Social Security Inquiry scheme information & $\begin{array}{c}100+ \\
\text { countries }\end{array}$ & Various & $\begin{array}{l}\text { International } \\
\text { Labour } \\
\text { Organization }\end{array}$ \\
\hline $\begin{array}{l}\text { Social Security Programs Throughout the } \\
\text { World country summaries }\end{array}$ & $\begin{array}{c}170 \\
\text { countries }\end{array}$ & $\begin{array}{l}2014 \text { (Asia); } \\
2013 \\
\text { (Africa) }\end{array}$ & $\begin{array}{l}\text { International Social } \\
\text { Security Association }\end{array}$ \\
\hline $\begin{array}{l}\text { Social Protection Index consultant country } \\
\text { reports }\end{array}$ & $\begin{array}{l}35 \text { countries } \\
\text { (Asia only) }\end{array}$ & 2012 & $\begin{array}{l}\text { Asian Development } \\
\text { Bank }\end{array}$ \\
\hline $\begin{array}{l}\text { Responses to call for submissions by Special } \\
\text { Rapporteur on the Rights of Persons with } \\
\text { Disabilities by member states, national } \\
\text { human rights institutions and civil society }\end{array}$ & $\begin{array}{c}50+ \\
\text { responses }\end{array}$ & 2015 & $\begin{array}{l}\text { Office of the High } \\
\text { Commissioner for } \\
\text { Human Rights }\end{array}$ \\
\hline $\begin{array}{l}\text { State Party Reports to Committee on the } \\
\text { Rights of Persons with Disabilities and } \\
\text { submissions by national human rights } \\
\text { institutions and civil society }\end{array}$ & $\begin{array}{l}5 \text { in Asia, } 10 \\
\text { in Africa }\end{array}$ & $2010-2015$ & $\begin{array}{l}\text { Committee on the } \\
\text { Rights of Persons } \\
\text { with Disabilities }\end{array}$ \\
\hline $\begin{array}{l}\text { Social Assistance in Developing Countries } \\
\text { Database Version } 5.0\end{array}$ & $\begin{array}{c}30+ \\
\text { countries }\end{array}$ & 2010 & $\begin{array}{l}\text { Brooks World } \\
\text { Poverty Institute, } \\
\text { University of } \\
\text { Manchester }\end{array}$ \\
\hline $\begin{array}{l}\text { Mapping report on social protection } \\
\text { programmes for people disabilities }\end{array}$ & 9 countries & 2014 & $\begin{array}{l}\text { Governance and } \\
\text { Social Development } \\
\text { Resource Centre }\end{array}$ \\
\hline Disability and social assistance database & $\begin{array}{c}30+ \\
\text { countries }\end{array}$ & 2013 & $\begin{array}{l}\text { International } \\
\text { Disability Alliance }\end{array}$ \\
\hline Disability Benefits Scheme Database & 56 countries & 2014 & $\begin{array}{l}\text { Development } \\
\text { Pathways }\end{array}$ \\
\hline
\end{tabular}


Table 3: Themes and sub-themes selected for data extraction

\begin{tabular}{|c|c|}
\hline \multirow{14}{*}{$\begin{array}{c}\text { General } \\
\text { information }\end{array}$} & Statutory or non-statutory \\
\hline & Public or private \\
\hline & Contributory or non-contributory \\
\hline & Social insurance, social assistance or labour market \\
\hline & Programme category (ASPIRE categories) \\
\hline & Programme sub-category (ASPIRE sub-categories) \\
\hline & Disability-specific or mainstream \\
\hline & Means-tested or universal \\
\hline & Cash or in-kind payment \\
\hline & Periodic, lump-sum or adhoc payment \\
\hline & Number of beneficiaries \\
\hline & Expenditure of programme (annual) \\
\hline & Administrative organisation \\
\hline & Benefits provided \\
\hline \multirow{7}{*}{$\begin{array}{l}\text { Disability } \\
\text { specific }\end{array}$} & Definition of disability \\
\hline & Inclusion criteria \\
\hline & Number of beneficiaries with disabilities \\
\hline & Budget allocation \\
\hline & Additional services / benefits \\
\hline & Relevant legislation \\
\hline & Participation mechanisms \\
\hline
\end{tabular}


Table 4: Total number of programmes identified by region and sub-region

\begin{tabular}{|l|l|l|l|}
\hline Region & $\begin{array}{l}\text { No. of } \\
\text { Countries }\end{array}$ & $\begin{array}{l}\text { Total No. } \\
\text { of Schemes }\end{array}$ & $\begin{array}{l}\text { Average No. } \\
\text { of Schemes }\end{array}$ \\
\hline Asia Pacific & $\mathbf{2 2}$ & $\mathbf{2 1 5}$ & $\mathbf{9 . 8}$ \\
\hline Eastern Asia & 2 & 25 & 12.5 \\
\hline Southern Asia & 6 & 100 & 16.7 \\
\hline South-Eastern Asia & 6 & 64 & 10.7 \\
\hline $\begin{array}{l}\text { Melanesia, Micronesia \& } \\
\text { Polynesia }\end{array}$ & 8 & 26 & 3.3 \\
\hline Africa & $\mathbf{3 0}$ & $\mathbf{1 5 1}$ & $\mathbf{5}$ \\
\hline Eastern Africa & 8 & 66 & 8.3 \\
\hline Middle Africa & 6 & 22 & 3.7 \\
\hline Northern Africa (only Sudan) & 1 & 2 & 2 \\
\hline Southern Africa & 4 & 23 & 5.8 \\
\hline Western Africa & 11 & 38 & 3.5 \\
\hline
\end{tabular}


Table 5: Categories of social protection programme, in Asia Pacific and Africa (number of programmes)

\begin{tabular}{|c|c|c|}
\hline \multirow{17}{*}{ Asia Pacific } & \multicolumn{2}{|l|}{ Social assistance } \\
\hline & Non-contributory social pension & 21 \\
\hline & Unconditional cash transfer & 3 \\
\hline & Conditional cash transfer & 6 \\
\hline & Food and cash transfer & 1 \\
\hline & Food and in-kind transfer & 6 \\
\hline & Fee-waivers and subsidies & 11 \\
\hline & Public works programmes & 2 \\
\hline & 'Other social assistance' ${ }^{*}$ & 36 \\
\hline & \multicolumn{2}{|l|}{ Social insurance } \\
\hline & Contributory pension & 28 \\
\hline & 'Other social insurance' ${ }^{* *}$ & 37 \\
\hline & \multicolumn{2}{|l|}{ Labour market } \\
\hline & Active labour market & 28 \\
\hline & Passive labour market & 2 \\
\hline & \multicolumn{2}{|l|}{ Other } \\
\hline & Unassigned or various & 6 \\
\hline \multirow{16}{*}{ Africa } & \multicolumn{2}{|l|}{ Social assistance } \\
\hline & Non-contributory social pension & 11 \\
\hline & Unconditional cash transfer & 12 \\
\hline & Conditional cash transfer & 5 \\
\hline & Food and in-kind transfer & 1 \\
\hline & Fee waivers and subsidies & 9 \\
\hline & Public works & 4 \\
\hline & 'Other' social assistance* & 4 \\
\hline & \multicolumn{2}{|l|}{ Social insurance } \\
\hline & Contributory pensions & 46 \\
\hline & 'Other' social insurance** & 39 \\
\hline & \multicolumn{2}{|l|}{ Labour market } \\
\hline & Active labour market & 15 \\
\hline & Passive labour market & 1 \\
\hline & \multicolumn{2}{|l|}{ Other } \\
\hline & Unassigned or various & 4 \\
\hline
\end{tabular}

* Includes social care services,

scholarships, health benefits,

transfers for care givers and

mixed schemes ('various').

** Includes health insurance,

occupational injuries benefits

and mixed schemes ('various'). 
Table 6: Benefits provided by social protection programmes, in Asia Pacific and Africa (number of programmes)

\begin{tabular}{|c|c|c|c|c|}
\hline & \multicolumn{2}{|c|}{ Asia Pacific } & \multicolumn{2}{|c|}{ Africa } \\
\hline \multirow{4}{*}{$\begin{array}{l}\text { Type of } \\
\text { Benefit }\end{array}$} & Cash & 97 & Cash & 90 \\
\hline & $\begin{array}{l}\text { Cash and in- } \\
\text { kind }\end{array}$ & 43 & $\begin{array}{l}\text { Cash and in- } \\
\text { kind }\end{array}$ & 38 \\
\hline & In-kind & 71 & In-kind & 22 \\
\hline & Uncategorised & 4 & Uncategorised & 1 \\
\hline \multirow{4}{*}{$\begin{array}{l}\text { Regular or } \\
\text { one-time }\end{array}$} & Periodic & 59 & Periodic & 45 \\
\hline & $\begin{array}{l}\text { Ad-hoc or } \\
\text { lump sum }\end{array}$ & 117 & $\begin{array}{l}\text { Ad-hoc or } \\
\text { lump sum }\end{array}$ & 36 \\
\hline & Both & 35 & Both & 66 \\
\hline & Uncategorised & 0 & Uncategorised & 4 \\
\hline
\end{tabular}


Figure 1: Percentage of social protection programmes that were non-contributory schemes by world region

Figure 2: Contributory and non-contributory schemes in Francophone and nonFrancophone Africa (excluding Mauritius)

Figure 3 - Types of social protection programmes (Asia, Africa, Francophone and NonFrancophone Africa)

Figure 4: Number of beneficiaries per scheme (Asia Pacific and Africa) 